\title{
Why do general practitioners prescribe antidepressants to their patients? A pilot study
}

\author{
Alain Mercier ${ }^{1,6^{*}}$, Isabelle Auger-Aubin ${ }^{2}$, Jean-Pierre Lebeau ${ }^{3}$, Matthieu Schuers ${ }^{1}$, Pascal Boulet ${ }^{1}$, \\ Paul Van Royen ${ }^{4}$ and Lieve Peremans $s^{4,5}$
}

\begin{abstract}
Background: The frequency of antidepressant (ADs) prescription is high, with general practitioners (GPs) responsible for about $80 \%$ of the prescriptions. Some studies considered prescriptions meet DSM criteria, while others stress inadequate use. The importance of biological and psychosocial determinants of GP prescription behaviour remains little explored. We aimed to describe the importance of these biological and psychosocial determinants and their weight in the daily practice of GPs'.
\end{abstract}

Methods: During a week chosen at random, 28 GPs collected the AD prescriptions made within the previous six months, regardless of the reason for the patient contact. Bio psychosocial and AD treatment characteristics were recorded for all patients. In a random sample of 50 patients, patient characteristics were assessed via a structured face-to-face interview with the GP.

Results: The frequency of AD prescription was 8.90\% [3.94 -17.02]. The GPs initiated 65.6\% [60.1-70.8] of the prescriptions. The rate of AD prescription for non-psychiatric conditions was 18\%. Patients had from 1 to 9 conditions, showing a high level of multi-morbidity. There was a strong influence of past medical history and contextual problems, such as work related problems.

Conclusion: AD prescription is related to complex contextual situations and multi-morbid patients. GPs use a bio psycho social approach, rather than a purely biological assessment. Awareness of these influences could improve prescription by GPS.

Keywords: Antidepressants, Primary care, General practitioner, Prescription, Off label use

\section{Background}

Antidepressant (AD) sales increased sevenfold in industrialized countries from 1980 to 2008 and have remained rather stable since then [1-3]. In the overall population, the 12-month rate of $\mathrm{AD}$ consumption ranges from $6 \%$ to nearly $10 \%[3-5]$. The AD consumption is very high in France (9.7\%) and in the USA (10.7\%) [6-8]. In all countries, General Practitioners (GPs) are responsible for about $80 \%$ of these prescriptions [2,9]. This high level of consumption could be explained by a greater demand for medical care and an increased number of patients treated for depression $[10,11]$. The increasing rate

\footnotetext{
* Correspondence: alain.mercier@univ-rouen.fr

'Department of General Practice, Rouen University and CIC Inserm 0204,

University of Rouen, Rouen, France

${ }^{6}$ Department of Family practice, Rouen University, Faculty of Medicine, $20 \mathrm{Bd}$

Gambetta, Rouen 76000, France

Full list of author information is available at the end of the article
}

of long-term treatment of depressed people could also explain this consumption [12]. ADs are also prescribed for other mental disorders, such as anxiety [13] and for minor depression [3,14]. ADs could also be adequately used in treating non-psychiatric conditions such as pain [15]. Some studies have shown that most patients (8695\%) diagnosed as depressed and treated by their GP with ADs met the DSM-IV depression criteria of a major depressive disorder (MDD) $[16,17]$. Others showed that the rate of off-label prescriptions varies between $20 \%$ and $60 \%$ of all prescribed ADs $[18,19]$. They are also prescribed in an inadequate manner, such as a too short duration of treatment [20] or in a sub-therapeutic dosage [3]. All these discrepancies suggest a lack of data, probably related to the complex real-life situations seen in primary care: Qualitative research has revealed that GPs usually prescribe ADs for non-psychiatric or mixed 
conditions, sometimes off-label, influenced by overall patient characteristics [21,22]. The relative influence of these factors on AD prescription among GPs remains unexplored, particularly regarding the characteristics of the patients' condition and their social environment. The main aim of this pilot study is to more precisely describe the importance of these biological and psychosocial determinants as they relate to GPs in their daily practice.

\section{Methods}

$\mathrm{AD}$ prescriptions and the characteristics of patients who had been prescribed an $\mathrm{AD}$ in the last six months were gathered.

\section{Pilot study participants and settings}

The study was conducted in the Normandy region of France, in the northwestern area of the country. Like many regions, it includes industrialized cities (e.g. Rouen, Le Havre) as well as rural areas and has an overall population of 1.9 million inhabitants. Access to the health care system does not differ from the usual standard of the country: In France, GPs are the first medical contact for the patients and provide open access to its users, dealing with all health problems regardless of the age, sex, or any other characteristic of the person concerned. A three year specialized curriculum, (or official equivalency) is mandatory to practice as a GP. All GPs from our local research network were invited to participate in the study. Those invited all worked full-time at a primary ambulatory care practice, only seeing outpatients. None of the physicians worked in specialized or secondary care settings (e.g. hospital, clinics).

\section{Data collection}

The GPs collected the data during a week chosen at random between December 2011 and March 2012. We included all patients who had been prescribed an $\mathrm{AD}$ within the previous six months, including renewals and new prescriptions, regardless of the reason for contact, and whether or not this prescription was continued later on. Patient characteristics (gender, age, socio-professional category and marital status) and the AD treatment characteristics (dosage, estimated starting date, and initiator of the prescription) were recorded. In order to focus in depth on all biological and psychosocial characteristics, we randomly selected from each GP two patients who had been prescribed an AD within the previous six months. The selection was stopped when a total of 50 patient files had been drawn. Once these files were selected, the patients' characteristics were assessed via a structured face-to-face interview with the GP. The assessment included risk factors for depression and on-label and off-label conditions for $\mathrm{AD}$ prescription. All other characteristics encountered during our previous qualitative analysis of $\mathrm{AD}$ prescription by GPs' were also collected [22]. Those characteristics were related to the psycho-social context of the patient (e.g. relational conflicts in the family, social loneliness, see Table 1), past history, and on-going conditions, as they were perceived by the GPs. During the interview, the GPs were asked to use information from the patient's file and to rate the influence of each characteristic for each $\mathrm{AD}$ prescription ("0" for no influence on their AD prescription, " 1 " for a slight influence and "2" for a major influence). The aim was to weight the relative influence of the factors for an AD prescription according to the GP himself. We wanted to point out the influence of less prevalent factors than psychiatric disorders (e.g. life events, pain conditions).

\section{Objectives and outcomes}

We wanted first to determine the number of AD prescriptions by the GPs, the characteristics of these prescriptions both for psychiatric and non-psychiatric conditions (name of $\mathrm{AD}$, dosage and duration of treatment), and the biological and psychosocial characteristics of the patients, including the patients' socio-professional category. Three categories - on-going problems, patient history, and biomedical conditions - were distinguished. Secondly, we assessed the influence of these determinants based on the interviews with the prescribing GPs.

Based on data regarding prescription of ADs for nonpsychiatric conditions, our initial hypothesis was that a $20 \%$ prevalence of $\mathrm{AD}$ prescriptions not related to any psychiatric condition would be found $[3,18]$. The other hypothesis was that the GPs' decision would be influenced by multiple factors related to the complexity of general practice situations.

\section{Analysis}

Data were collected using Excel ${ }^{\oplus}$. Any outlier and missing data were tracked. A descriptive analysis was performed using "epi-info ${ }^{\circ} 3.53$ ". To get an indication of the weight of the influencing factors for the 50 randomly chosen patients, the sum of all individual determinant scores, rated from 0 to 2 for each patient, was calculated. The mean number and range of influencing factors per patient as well as the modus score for each influencing factor was determined. We determined the strength of influence by dividing the score of influence by the prevalence for each factor.

\section{Ethical aspects}

The local ethics committee (CPP Nord-Ouest) stated that an authorization was not required for this noninterventional study.

\section{Results \\ GP characteristics}

Among the 56 GPs invited, 28 (6 females and 22 males) agreed to participate. The mean age was 48.5 years (32-63; 
Table 1 Diagnosis, psychosocial context, past history, and ongoing conditions $(n=50)$

\begin{tabular}{|c|c|c|c|c|c|c|}
\hline \multirow{2}{*}{ Gender } & & \multirow{2}{*}{$\begin{array}{c}\begin{array}{c}\text { All patients } \\
\mathrm{n}=50\end{array} \\
\\
34\end{array}$} & \multirow{2}{*}{$\begin{array}{c}\text { All patients with at } \\
\text { least one psychiatric } \\
\text { diagnosis }^{(1)} n=41\end{array}$} & \multirow{2}{*}{$\begin{array}{c}\text { All patients with } \\
\begin{array}{c}\text { a depressive } \\
\text { episode }^{(2)} n=31\end{array} \\
21\end{array}$} & \multirow{2}{*}{$\begin{array}{c}\text { All patients with a } \\
\text { major depressive } \\
\text { episode (intense) } \\
n=20 \\
13\end{array}$} & \multirow{2}{*}{$\begin{array}{c}\begin{array}{r}\text { All patients with } \\
\text { no psychiatric } \\
\text { diagnosis } n=9\end{array} \\
5\end{array}$} \\
\hline & Female & & & & & \\
\hline Age & Mean/Range & $52.8[19-91]$ & 50.6 [19-91] & 48.8 [19-91] & $45.8[19-77]$ & $62[40-84]$ \\
\hline Job & Professional activity & 26 & 22 & 17 & 11 & 3 \\
\hline \multirow{3}{*}{$\begin{array}{l}\text { Socio- professional } \\
\text { class }\end{array}$} & Low income & 19 & 17 & 11 & 7 & 2 \\
\hline & Intermediate to high income/ & 15 & 12 & 11 & 9 & 3 \\
\hline & retirement & 16 & 12 & 9 & 4 & 4 \\
\hline \multirow[t]{4}{*}{ Marital status } & Living together/Married & 21 & 15 & 17 & 4 & 8 \\
\hline & Single, Divorced, separation & 19 & 17 & 15 & 12 & 0 \\
\hline & Widowed & 10 & 9 & 9 & 4 & 1 \\
\hline & Relational conflicts in family & 18 & 17 & 15 & 11 & 1 \\
\hline \multirow[t]{12}{*}{ Current context } & Disability (official status) & 8 & 6 & 5 & 3 & 2 \\
\hline & $\begin{array}{l}\text { Social loneliness/Socially } \\
\text { isolated patient }\end{array}$ & 5 & 5 & 5 & 5 & 0 \\
\hline & Work-related problems & 17 & 14 & 10 & 5 & 3 \\
\hline & $\begin{array}{l}\text { Legal problems/Current } \\
\text { legal situation }\end{array}$ & 4 & 4 & 4 & 4 & 0 \\
\hline & $\begin{array}{l}\text { Recent bereavement/Recent } \\
\text { death in the entourage }\end{array}$ & 12 & 9 & 9 & 5 & 3 \\
\hline & Position of family care giver & 7 & 7 & 5 & 3 & 0 \\
\hline & $\begin{array}{c}\text { Patient physically or } \\
\text { psychologically dependent }\end{array}$ & 7 & 7 & 6 & 4 & 0 \\
\hline & Facing discrimination & 5 & 5 & 4 & 2 & 0 \\
\hline & $\begin{array}{l}\text { Current tobacco } \\
\text { consumption }\end{array}$ & 14 & 12 & 10 & 6 & 2 \\
\hline & $\begin{array}{l}\text { Excessive alcohol } \\
\text { consumption }\end{array}$ & 3 & 3 & 2 & 2 & 0 \\
\hline & $\begin{array}{c}\text { Other addictions (Opiates, } \\
\text { gambling, etc.) }\end{array}$ & 6 & 5 & 4 & 3 & 1 \\
\hline & $\begin{array}{l}\text { Substitution therapy } \\
\text { (methadone, buprenorphine) }\end{array}$ & 1 & 1 & 1 & 1 & 0 \\
\hline \multicolumn{2}{|c|}{ Number of contextual factors by patient Mean/Range } & $2.1[0-6]$ & $2.31[0-6]$ & $2.7[0-6]$ & $2.6[0-6]$ & $1.33[0-4]$ \\
\hline \multirow{9}{*}{$\begin{array}{l}\text { Past history of } \\
\text { patient }\end{array}$} & Past history of suicide attempt & 6 & 6 & 4 & 3 & 0 \\
\hline & Tobacco consumption & 18 & 15 & 12 & 8 & 3 \\
\hline & $\begin{array}{l}\text { Past history of excessive } \\
\text { alcohol consumption }\end{array}$ & 7 & 6 & 5 & 5 & 1 \\
\hline & $\begin{array}{l}\text { Other addictions } \\
\text { (e.g. opiates, gambling) }\end{array}$ & 4 & 3 & 4 & 3 & 1 \\
\hline & $\begin{array}{c}\text { Past history of depression } \\
\text { (different from current } \\
\text { episode) }\end{array}$ & 19 & 18 & 14 & 8 & 1 \\
\hline & $\begin{array}{c}\text { Past history: Hospitalised in } \\
\text { psychiatric service, whatever } \\
\text { the reason }\end{array}$ & 5 & 5 & 3 & 2 & 0 \\
\hline & $\begin{array}{l}\text { Family with psychiatric } \\
\text { conditions }\end{array}$ & 10 & 9 & 5 & 5 & 1 \\
\hline & Past history of $A D$ prescription & 23 & 22 & 15 & 9 & 1 \\
\hline & Child abuse & 5 & 4 & 3 & 3 & 1 \\
\hline
\end{tabular}


Table 1 Diagnosis, psychosocial context, past history, and ongoing conditions $(\mathbf{n}=\mathbf{5 0}$ ) (Continued)

\begin{tabular}{|c|c|c|c|c|c|c|}
\hline \multicolumn{2}{|c|}{ Number of past history factors by patient } & $2.1[0-6]$ & $2.1[0-6]$ & $2.3[0-6]$ & $2.0[0-9]$ & $1[0-3]$ \\
\hline \multirow{14}{*}{$\begin{array}{l}\text { Ongoing, non-psychiatric } \\
\text { conditions }\end{array}$} & Isolated sleeping problems & 6 & 2 & 0 & 0 & 4 \\
\hline & Dementia & 2 & 1 & 0 & 0 & 1 \\
\hline & Specific neuropathic pain & 3 & 1 & 1 & 1 & 2 \\
\hline & Sciatic pain & 3 & 3 & 2 & 2 & 0 \\
\hline & Migraine & 3 & 2 & 1 & 0 & 1 \\
\hline & Fibromyalgia & 3 & 1 & 1 & 1 & 2 \\
\hline & $\begin{array}{l}\text { Musculo-skeletal complaints } \\
\text { or pain }\end{array}$ & 16 & 14 & 13 & 7 & 2 \\
\hline & Tension type headaches & 7 & 7 & 4 & 3 & 0 \\
\hline & Isolated fatigue & 10 & 9 & 7 & 3 & 1 \\
\hline & $\begin{array}{c}\text { Functional gastro-intestinal } \\
\text { complaints: Irritable bowel } \\
\text { syndrome }\end{array}$ & 12 & 9 & 6 & 0 & 3 \\
\hline & $\begin{array}{l}\text { Sexual dysfunction, } \\
\text { premature ejaculation }\end{array}$ & 5 & 4 & 3 & 3 & 1 \\
\hline & Enuresis, incontinence & 3 & 3 & 3 & 2 & 0 \\
\hline & $\begin{array}{l}\text { Other chronic disease } \\
\text { (e.g. Diabetes type 2) }\end{array}$ & 35 & 25 & 19 & 11 & 7 \\
\hline & Chronic low back pain & 6 & 5 & 2 & 2 & 1 \\
\hline \multicolumn{2}{|c|}{$\begin{array}{l}\text { Number of non-psychiatric conditions by patient } \\
\text { Mean/Range }\end{array}$} & $2.28[0-7]$ & $2.09[0-7]$ & $1.75[0-6]$ & $2.0[0-7]$ & $2.77[1-5]$ \\
\hline \multirow{3}{*}{$\begin{array}{l}\text { Ongoing non-psychiatric } \\
\text { reasons }\end{array}$} & Chronic diffuse complaints & 12 & 12 & 10 & 6 & 0 \\
\hline & Unexplained complaints & 13 & 11 & 8 & 3 & 2 \\
\hline & Diffused pain & 8 & 7 & 4 & 2 & 1 \\
\hline \multicolumn{2}{|c|}{ All reasons and conditions by patient Mean/Range } & $4.1[1-9]$ & $4.2[1-9]$ & 3.9 [1-9] & $4.22[1-9]$ & $3.2[1-5]$ \\
\hline
\end{tabular}

${ }^{1}$ All psychiatric conditions, including symptoms of depression without all criteria for a major episode, all diagnoses of anxiety.

${ }^{2}$ All depressive episodes, whatever the intensity.

${ }^{3}$ Major depressive episodes only.

$\mathrm{SD}=9.5$ ). Nine worked in rural practice, and 14 were mentoring students. The mean duration of practice was 17.8 years $(3-35 ; \mathrm{SD}=10.5)$. The mean number of patients met during the week of the study was 126 (56-260; SD = 40.4).

\section{Overall patient characteristics}

During the study week, the GPs saw 3,522 patients, 317 of whom (8.90\%; [3.94 -17.02]) were prescribed an AD. Two hundred twenty-nine patients were female $(72.2 \%$ [67-77.1]) and $88(27.8 \%$ [23-33.1]) male. Their mean age was 54 [18-91]. Fifty-six per cent $(n=178)$ were married or living together; the others were single $(\mathrm{n}=50$ [16\%]), divorced $(n=48[15 \%])$ or widowed $(n=41[13 \%]$. Most patients belonged to a low-income social class $(\mathrm{n}=68$ [52\%]). Overall, 235 patients (74.1\% [68.9-78.9]) were prescribed "new" ADs (SSRIs and SNRIs). For more than one in four patients, the AD treatment was initiated during the previous six months $(\mathrm{n}=83[26 \%])$. The participating GPs themselves initiated 208 prescriptions (65.6 [60.1-70.8]). During the study week every GP had nearly three patients (2.96) for whom they initiated an $\mathrm{AD}$ prescription.

\section{In-depth assessment of the 50-patient sample}

The results are described in Table 1 . Half of the patients had no professional activity and 17 had work-related problems. Nine patients had no diagnosis of any psychiatric condition. According to their GP, the other 41 had a psychiatric diagnosis: major depressive episode, depressive episode or anxiety, or sometimes a combination. On the whole, patients had from 1 to 9 reasons or conditions, $($ mean $=4.1)$ and from 0 to 8 non-psychiatric conditions $($ mean $=2.94)$, showing a high level of multimorbidity. Many of these conditions were related to pain.

The prevalence of the conditions assessed and their most frequent influence score are shown in Table 2. The relative influence for the most important of them is shown in Table 3. Among the contextual factors, work-related problems and recent bereavement showed both a high prevalence and strong influence on $\mathrm{AD}$ prescription. 
Table 2 Influence, prevalence, and modus of influence of each factor $(n=50)$

\begin{tabular}{|c|c|c|c|c|}
\hline Type of situation & Condition or characteristic & $\begin{array}{l}\text { Total score of } \\
\text { Influence }{ }^{(1)}(\mathrm{n})\end{array}$ & Prevalence $^{(2)}(n)$ & $\begin{array}{l}\text { Most frequent influence } \\
\text { score }^{(3)} \text { (modus) }\end{array}$ \\
\hline \multirow[t]{4}{*}{ Psychiatric conditions } & Anxiety (all) & 41 & 24 & 2 \\
\hline & Major depressive episode (intense) & 40 & 20 & 2 \\
\hline & Depressive episode (mild) & 20 & 11 & 2 \\
\hline & $\begin{array}{c}\text { Symptoms of bad mood without } \\
\text { depression }\end{array}$ & 4 & 3 & 1 \\
\hline \multirow{6}{*}{$\begin{array}{l}\text { Psychiatric-related } \\
\text { past history }\end{array}$} & Past history of $A D$ prescription & 30 & 23 & 2 \\
\hline & Past history of depression & 24 & 19 & $1 / 2$ \\
\hline & Family with psychiatric conditions & 8 & 10 & 1 \\
\hline & Past history of suicide attempt & 7 & 7 & 1 \\
\hline & $\begin{array}{l}\text { Past history of excessive alcohol } \\
\text { consumption }\end{array}$ & 4 & 6 & 0 \\
\hline & $\begin{array}{c}\text { Past history: Hospitalised in psychiatric } \\
\text { ward }\end{array}$ & 4 & 5 & 1 \\
\hline \multirow[t]{14}{*}{$\begin{array}{l}\text { Non-psychiatric } \\
\text { conditions }\end{array}$} & $\begin{array}{l}\text { Other chronic disease (e.g.: Diabetes } \\
\text { type } 2 \text { ) }\end{array}$ & 22 & 35 & 0 \\
\hline & Musculo- skeletal complaints or pain & 11 & 16 & 0 \\
\hline & Isolated fatigue & 11 & 10 & 2 \\
\hline & Isolated sleeping problems & 7 & 6 & $0 / 1$ \\
\hline & $\begin{array}{l}\text { Functional gastro-intestinal complaints: } \\
\text { Irritable bowel syndrome }\end{array}$ & 5 & 12 & 0 \\
\hline & Sexual dysfunction, premature ejaculation & 5 & 5 & $0 / 2$ \\
\hline & Specific neuropathic pain & 5 & 3 & 2 \\
\hline & Tension type headaches & 4 & 7 & 0 \\
\hline & Fibromyalgia & 4 & 3 & 2 \\
\hline & Chronic low back pain & 3 & 6 & 0 \\
\hline & Migraine & 2 & 3 & 0 \\
\hline & Dementia & 2 & 2 & $0 / 2$ \\
\hline & Sciatica pain & 1 & 3 & 0 \\
\hline & Enuresis, incontinence & 0 & 3 & 0 \\
\hline \multirow{3}{*}{$\begin{array}{l}\text { Non- psychiatric } \\
\text { reasons }\end{array}$} & Chronic complaints & 13 & 12 & 1 \\
\hline & Unexplained complaints & 10 & 13 & 1 \\
\hline & Diffused pain & 10 & 8 & 2 \\
\hline \multirow{3}{*}{$\begin{array}{l}\text { Non- psychiatric past } \\
\text { history }\end{array}$} & Past history of mistreatment/child abuse & 5 & 5 & 1 \\
\hline & Past history of tobacco consumption & 2 & 18 & 0 \\
\hline & Past history of other addictions (e.g. Gambling) & 1 & 5 & 0 \\
\hline \multirow[t]{9}{*}{ Other factors } & Work-related problems & 23 & 17 & 2 \\
\hline & $\begin{array}{l}\text { Recent bereavement/Recent death in } \\
\text { entourage }\end{array}$ & 15 & 12 & 2 \\
\hline & Legal problems/Current legal situation & 8 & 4 & 2 \\
\hline & Position of family care giver & 7 & 7 & 1 \\
\hline & Physically or psychologically dependent patient & 6 & 7 & 0 \\
\hline & Facing discrimination & 6 & 5 & 1 \\
\hline & Social loneliness/Socially isolated patient & 6 & 5 & 1 \\
\hline & Disability (official status) & 5 & 8 & 0 \\
\hline & Current tobacco consumption & 2 & 14 & 0 \\
\hline
\end{tabular}


Table 2 Influence, prevalence, and modus of influence of each factor $(\mathbf{n}=\mathbf{5 0})$ (Continued)

Other addictions (Opiates, gambling, etc.)
Excessive alcohol consumption
Replacement therapy (methadone,
buprenorphine)

Within the past medical history, former AD prescription and depression were noticeably prevalent. Fibromyalgia and neuropathic pain, though not so prevalent, nonetheless had a strong influence on the decision to prescribe an $\mathrm{AD}$. Among the nine patients without a psychiatric disease, the conditions often associated were fibromyalgia $(n=2)$, pain $(\mathrm{n}=2)$, premature ejaculation $(\mathrm{n}=1)$, sleeping troubles ( $\mathrm{n}=3$, 2 for a withdrawal process), exhausted family caregiver $(n=1)$ serious grief $(n=1)$. Other chronic diseases for which an $\mathrm{AD}$ was prescribed included disability after a stroke and chronic cardiac failure.

\section{Discussion}

\section{Prescription of ADs: characteristics}

This study confirmed the high frequency of AD prescription in general practice. Nevertheless, one third of

Table 3 Strength of influence for the main factors

\begin{tabular}{|c|c|}
\hline Condition or characteristic & Influence score $(*)$ \\
\hline Major depressive episode (intense) & 2 \\
\hline Legal problems/Current legal situation & 2 \\
\hline Depressive episode (mild) & 1.8 \\
\hline Anxiety (all) & 1.7 \\
\hline Specific neuropathic pain & 1.6 \\
\hline Work-related problems & 1.3 \\
\hline Symptoms of bad mood without depression & 1.3 \\
\hline Past history of AD prescription & 1.3 \\
\hline Past history of depression & 1.3 \\
\hline Fibromyalgia & 1.3 \\
\hline Recent bereavement/Recent death in entourage & 1.2 \\
\hline Facing discrimination & 1.2 \\
\hline Social loneliness/Socially isolated patient & 1.2 \\
\hline Diffused pain & 1.2 \\
\hline Isolated fatigue & 1.1 \\
\hline Isolated sleeping problems & 1.1 \\
\hline Sexual dysfunction, premature ejaculation & 1 \\
\hline Past history of suicide attempt & 1 \\
\hline Dementia & 1 \\
\hline Past history of mistreatment/child abuse & 1 \\
\hline Position of family care giver & 1 \\
\hline
\end{tabular}

(*) The influence was determined by dividing the score of influence by the prevalence for each factor. the AD prescriptions were not initiated by the GPs, but were renewals. The rate of $\mathrm{AD}$ prescription varied considerably, from $4 \%$ to $17 \%$ per GP, as has been observed in other studies [23]. One patient in four (26\%) had recently been prescribed an AD, initiated by his own GP. During the study week, each of the GPs saw an average of 11 patients taking ADs: On average eight of the patients were already taking the $\mathrm{AD}$ and the physician initiated the prescription for the other three. One patient in two had had a long-term prescription, more than one year, which is consistent with other studies $[10,12]$.

\section{Patient characteristics}

The most prevalent and influential conditions were anxiety and depression, in contradiction with other studies $[6,18]$. According to their GP, $76 \%$ of the patients presented with a full psychiatric condition. Women were particularly affected. Only $6 \%$ of the patients presented isolated psychological symptoms, and $18 \%$ no psychiatric condition at all. The fact that anxiety was an important reason for $\mathrm{AD}$ prescription must be highlighted, though anxiety is partly associated with depression. French health authorities have stigmatised the prescription of benzodiazepines by GPs and their level of prescription has stagnated [3], which has probably produced a shift away from benzodiazepines towards more AD prescriptions. The influence of a past history of depression or previous $\mathrm{AD}$ prescription has also to be pointed out, as it was already suggested from our previous qualitative study [22]. Current use and past history of tobacco consumption were highly common, a phenomenon previously known among these categories of patients [24].

\section{The importance of psychosocial situations}

In addition to already known risk factors for depression and psychiatric problems, the GPs underlined the influences of psychosocial factors. They reported that work related problems had an important influence on their decision. Legal problems, recent grief, and discrimination or social isolation also strongly influenced the GPs' decisions. This study also confirmed previously known factors for psychological and social distress: More than half of the patients were single, divorced or widowed, and belonged to a low-income social class. 


\section{The importance of non-psychiatric conditions}

For almost $20 \%$ of the enrolled patients, the reason for an $\mathrm{AD}$ prescription was a non-psychiatric condition. Many of the patients suffered from numerous on-going conditions. These conditions were also present as well in the case of psychiatric diseases as a co-morbid condition. The GPs decided to prescribe ADs for chronic nonpsychiatric conditions such as chronic complaints, pain, or sleep-related problems. Many of these non-psychiatric conditions (pain, migraine, fibromyalgia migraine, and premature ejaculation) met the criteria for scientific evidence for the prescription of ADs [15,25-28]. This level of evidence was lacking for some other conditions that influenced GPs, e.g. isolated sleep related problems or sciatica and low back pain, but these conditions were not the sole reason for prescription to these patients. They also had chronic ischemic artery conditions and type 2 diabetes, but the presence of these other chronic "physical" diseases was said to be of little influence. Only one patient was prescribed an AD mainly for restless legs syndrome, which is in fact a well-known side effect of ADs.

\section{Implications for practice}

Many of these AD prescriptions, including those for non-psychiatric conditions, seemed scientifically justified. We did not find "unexplained" prescriptions, but this did not mean that all of them were fully appropriate. Thus, these results indicate areas for improvement.

Firstly, the GPs should be aware of the influence of their patients 'context of life, such as family or work related problems, on their prescription behaviour. A bio psycho social approach, patient's centered, is therefore relevant in PC settings: It helps to build the relationship and to understand the patients' perspective in cases of stressful life events. These events seem to have too much influence on the AD prescription decisions of GPs.

Secondly, at the opposite, patients with chronic diseases did not seem to trigger $\mathrm{AD}$ prescriptions, even though they are a well-known factor for depression, sometimes leading to higher morbidity outcomes [29]. Do GPs pay enough attention of mood disturbances amongst these patients?

Thirdly the important number of patients for whom the prescription was not initiated by the GP himself has to be underlined: We do not know how these prescriptions are re-assessed. Their appropriateness should be questioned.

\section{Implications for a broader study}

This pilot study also specifically assessed the feasibility of a larger study. The aim will be to confirm these findings with a representative GP population sample. We sought to precisely present the rate of "prescriptions for nonpsychiatric conditions". Based on the outcome of this pilot study (i.e. an $18 \%$ rate of $\mathrm{AD}$ prescriptions for nonpsychiatric conditions), with a 95\% confidence interval, a sample of $600 \mathrm{AD}$ prescriptions will be required in order to obtain a minimum of 120 non-psychiatric prescriptions. With three prescriptions assessed for each GP, an intracluster correlation coefficient of 0.01 must be taken into account. The required sample of patient files and GPs will be 612 and 204 respectively. As a result, the mean number of patients eligible per week for the main study can roughly be estimated at three per GP per week. Taking into account Lasagna's law for prevalence studies, we can assume that two eligible patients per week is probably more realistic [30].

\section{Implication for further research}

We observed that some GPs prescribed ADs four times less frequently than others. Many hypotheses can be made. Differences in consumption could be related to differences between areas or countries [5]. Urbanization could influence the prevalence of mood disorders [31]. Patient characteristics, physician characteristics, the health care system, and interactions between these three components, all influence AD prescription [32]. The medical curriculum can influence the ability of the GPs to recognize and treat mood disorders [33]. In a full study, the influence of the GPs' practice location, their conviction regarding the efficacy of ADs, the number of patients seen, and the organization of the practice (solo or group practice) on AD prescription rate should be explored. Two other problems should be taken into account, i.e. a possible memory bias and under-recording of $\mathrm{AD}$ prescriptions. To ensure representativeness, the rate of $\mathrm{AD}$ prescriptions during four weeks of inclusion will be compared with the rate of annual $\mathrm{AD}$ prescription according to the French social security system. One challenge will be to understand differences in the rates of AD prescription by individual GPs and to interpret their prescription behaviour. This study, using a mixed-method design, will provide the chance to set up an opportunistic sample to perform qualitative interviews among these GPs in order to disclose their conception of care and their style of practice that potentially influences their $\mathrm{AD}$ prescriptions.

\section{Strengths and weaknesses}

This study assessed the influence of all patient characteristics according to the GPs, but was not designed to assess the reliability of their diagnosis with a standardized questionnaire. Thus, the level of appropriateness of $\mathrm{AD}$ prescription for depression and anxiety should be interpreted with caution. Psychiatric co morbidities are frequently associated in depressed people. Personality disorders could range for $25 \%$ of the patients treated with ADs. The presence of these disorders seems to negatively impact 
treatment outcomes [34]. In our study, the GPs disclosed prescription for several patients having "symptoms of depression" without all the items of the DSM 5 major depressive episode. Only a precise assessment of the patient's symptoms and personality could have provided an answer on fully appropriate or inappropriate AD prescriptions. Nevertheless this is a difficult challenge and subject of debate among psychiatrists. Medicalization of sadness in the context of our society is also an important issue, as people complain but are not being assessed as depressed by standardized instruments. Horwitz pointed out the changing conception of sadness and depression in our modern world [35]. For him, the limits of the concept of "depressive disorder" are vague. In the context of medicalization of life problems, it is tempting for the GP to analyse complaints only from a medical point of view. This could lead them to treat only symptoms of anxiety or sadness as a mental disorder.

Another possible bias could be different ways of practice among the GP participants: It is likely that GPs mentoring students are more prone to follow EBM guidelines. Such a behaviour could lower the rate of overall $\mathrm{AD}$ prescription and change the relative weight of the factors influencing the AD prescription. Nevertheless, the figures on the rate of prescription for non-psychiatric conditions were consistent with the range of calculations made based on the available literature. Collaboration of the GPs, availability of the data, and comprehensibility of the questionnaire were ensured, which is consistent with good internal and external validities. This is a pilot study: All of these data have allowed us to precisely design the protocol of a full study that will be done in order to validate these preliminary results in a larger population.

\section{Conclusion}

The mean rate of $\mathrm{AD}$ prescription by GPs was nearly $9 \%$. Among these, nearly $20 \%$ were prescriptions for non-psychiatric conditions. Non-psychiatric prescriptions were mainly related to complex contextual situations and multi-morbid patients. These preliminary results emphasise the influence of social and psychological factors in the GP's decision for this prescription. This pilot study ensures the feasibility of our upcoming study that aims to more precisely assess the reasons for and influences on this prescription behaviour.

\section{Competing interests}

The authors declare they have no conflict of interest.

\section{Authors' contributions}

Conception of the idea for the study: AM. Development of the protocol: AM, IAA, JPL, MS, PB. Data collection and extraction: AM, IAA, JPL. Critical assessment: AM, IAA, JPL, PB. PVR and LP participated in the design and coordination and helped to draft the manuscript. Writing of the manuscript:
AM. All of the authors have read the draft critically, to make contributions, and have approved the final text.

\section{Acknowledgements}

We thank the Scientific Committee of the CIC-INSERM-Rouen University Hospital for reviewing the protocol corresponding to this study. Thanks to our English editor, Stephen Martin, for his proofreading and advice.

\section{Author details}

'Department of General Practice, Rouen University and CIC Inserm 0204 University of Rouen, Rouen, France. ${ }^{2}$ Department of General Practice, Denis Diderot Paris 7 University, Paris, France. ${ }^{3}$ Department of General Practice, Tours University, Tours, France. ${ }^{4}$ Department of Primary and Interdisciplinary Care, Faculty of Medicine and Health Science, University of Antwerp, Antwerp, Belgium. ${ }^{5}$ Department of Public Health, Vrije Universiteit Brussel, Brussels, Belgium. ${ }^{6}$ Department of Family practice, Rouen University, Faculty of Medicine, 20 Bd Gambetta, Rouen 76000, France.

Received: 21 April 2014 Accepted: 25 July 2014

Published: 30 July 2014

\section{References}

1. Lépine J-P, Gasquet I, Kovess V, Arbabzadeh-Bouchez S, Nègre-Pagès L, Nachbaur G, Gaudin A-F: [Prevalence and comorbidity of psychiatric disorders in the French general population]. Encéphale 2005, 31:182-194.

2. Olié JP, Elomari F, Spadone C, Lépine JP: [Antidepressants consumption in the global population in France]. Encéphale 2002, 28:411-417.

3. Gasquet I, Nègre-Pagès L, Fourrier A, Nachbaur G, El-Hasnaoui A, Kovess V, Lépine J-P: [Psychotropic drug use and mental psychiatric disorders in France; results of the general population ESEMED/MHEDEA 2000 epidemiological study]. Encéphale 2005, 31:195-206.

4. Serna C, Cruz I, Galván L, Real J, Gascó E, Soler-González J: Evolution of the prevalence and incidence of consumption of antidepressants in a Spanish region (2002-2007). Ment Health Fam Med 2010, 7:9-15.

5. Ohayon MM, Lader MH: Use of psychotropic medication in the genera population of France, Germany, Italy, and the United Kingdom. J Clin Psychiatry 2002, 63:817-825.

6. Lecadet J J: Médicaments psychotropes : consommation et pratiques de prescription en France métropolitaine. I. Données nationales, 2000. Rev Med Mal 2003, 34

7. Ventes de médicaments aux officines et aux hôpitaux en france:chiffres clés 2010. Rapport d'expertise. Available at: http://ansm.sante.fr/var/ansm_site/ storage/original/application/c66c522fa172251d7588e4086475dd1 b.pdf [Last consulted on October 2, 2011].

8. Olfson M, Marcus SC: National patterns in antidepressant medication treatment. Arch Gen Psychiatry 2009, 66:848-856.

9. Mojtabai R, Olfson M: National patterns in antidepressant treatment by psychiatrists and general medical providers: results from the national comorbidity survey replication. J Clin Psychiatry 2008, 69:1064-1074.

10. Briot M, Assemblée Nationale. Office Parlementaire d'Evaluation des Politiques de Santé (OPEPS): Le bon usage des médicaments psychotropes. Paris: Assemblée Nationale, Rapport d'information de l'Assemblée Nationale; n³187; 2006:501. B5457 http://www.assemblee-nationale.fr/12/rap-off/i3187.asp [Last consulted on December 2013].

11. Lamboy B, Léon C, Guilbert P: Troubles dépressifs et recours aux soins dans la population française à partir des données du Baromètre Santé 2005. Rev Épidémiologie Santé Publique 2007, 55:222-227.

12. Moore M, Yuen HM, Dunn N, Mullee MA, Maskell J, Kendrick T: Explaining the rise in antidepressant prescribing: a descriptive study using the general practice research database. BMJ 2009, 339:b3999.

13. Ballenger JC, Davidson JR, Lecrubier Y, Nutt DJ, Borkovec TD, Rickels K, Stein DJ, Wittchen $\mathrm{HU}$ : Consensus statement on generalized anxiety disorder from the International Consensus Group on Depression and Anxiety. J Clin Psychiatry 2001, 62(Suppl 11):53-58.

14. Sleath $B$, Shih $Y-C T$ : Sociological influences on antidepressant prescribing. Soc Sci Med 2003, 56:1335-1344.

15. Dharmshaktu P, Tayal V, Kalra BS: Efficacy of antidepressants as analgesics: a review. J Clin Pharmacol 2011, 52:6-17.

16. Tardieu S, Bottero A, Blin P, Bohbot M, Goni S, Gerard A, Gasquet I: Roles and practices of general practitioners and psychiatrists in management of depression in the community. BMC Fam Pract 2006, 7:5. 
17. Piek E, van der Meer K, Hoogendijk WJG, Penninx BWJH, Nolen WA: Most Antidepressant Use in Primary Care Is Justified; Results of the Netherlands Study of Depression and Anxiety. PLoS One 2011, 6:e14784.

18. Mojtabai R, Olfson M: Proportion Of Antidepressants Prescribed Without A Psychiatric Diagnosis Is Growing. Health Aff (Millwood) 2011, 30:1434-1442.

19. Larson MJ, Miller K, Fleming KJ: Treatment with antidepressant medications in private health plans. Adm Policy Ment Health 2007, 34:116-126.

20. Briffault X, Morvan Y, Rouillon F, Dardennes R, Lamboy B: [Use of services and treatment adequacy of major depressive episodes in France]. Encéphale 2010, 36(Suppl 2):D48-D58.

21. Demyttenaere K, Bonnewyn A, Bruffaerts R, De Girolamo G, Gasquet I, Kovess V, Haro JM, Alonso J: Clinical factors influencing the prescription of antidepressants and benzodiazepines: results from the European study of the epidemiology of mental disorders (ESEMeD). J Affect Disord 2008, 110:84-93.

22. Mercier A, Auger-Aubin I, Lebeau J-P, Van Royen P, Peremans L: Understanding the prescription of antidepressants: a qualitative study among French GPs. BMC Fam Pract 2011, 12:99.

23. Ornstein $\mathrm{S}$, Stuart $\mathrm{G}$, Jenkins R: Depression diagnoses and antidepressant use in primary care practices: a study from the Practice Partner Research Network (PPRNet). J Fam Pract 2000, 49:68-72.

24. Ziedonis D, Hitsman B, Beckham JC, Zvolensky M, Adler LE, Audrain-McGovern J, Breslau N, Brown RA, George TP, Williams J, Calhoun PS, Riley WT: Tobacco use and cessation in psychiatric disorders: National Institute of Mental Health report. Nicotine Tob Res 2008, 10:1691-1715.

25. Ruepert L, Quartero AO, De Wit NJ, van der Heijden GJ, Rubin G, Muris JW: Bulking agents, antispasmodics and antidepressants for the treatment of irritable bowel syndrome. Cochrane Database Syst Rev Online 2011, 8:CD003460.

26. Jackson JL, Shimeall W, Sessums L, Dezee KJ, Becher D, Diemer M, Berbano E, O'Malley PG: Tricyclic antidepressants and headaches: systematic review and meta-analysis. BMJ 2010, 341:C5222.

27. Hatzimouratidis K, Amar E, Eardley I, Giuliano F, Hatzichristou D, Montorsi F, Vardi Y, Wespes E: Guidelines on male sexual dysfunction: erectile dysfunction and premature ejaculation. Eur Urol 2010, 57:804-814.

28. Mercier A, Auger-Aubin I, Lebeau J-P, Schuers M, Boulet P, Hermil J-L, Royen PV Peremans $L$ : Evidence of prescription of antidepressants for non-psychiatric conditions in primary care: an analysis of guidelines and systematic reviews. BMC Fam Pract 2013, 14:55.

29. Pizzi C, Rutjes AWS, Costa GM, Fontana F, Mezzetti A, Manzoli L: Meta-analysis of selective serotonin reuptake inhibitors in patients with depression and coronary heart disease. Am J Cardiol 2011, 107:972-979.

30. Van der Wouden JC, Blankenstein AH, Huibers MJH, van der Windt DAWM, Stalman WAB, Verhagen AP: Survey among 78 studies showed that Lasagna's law holds in Dutch primary care research. J Clin Epidemiol 2007, 60:819-824

31. Peen J, Schoevers RA, Beekman AT, Dekker J: The current status of urban-rural differences in psychiatric disorders. Acta Psychiatr Scand 2010, 121:84-93.

32. Sleath B, Shih Y-CT: Sociological influences on antidepressant prescribing. Soc Sci Med 1982, 56(6):1335-1344.

33. Van Os TW, van den Brink RH, Tiemens BG, Jenner JA, van der Meer K, Ormel J: Are effects of depression management training for General Practitioners on patient outcomes mediated by improvements in the process of care? J Affect Disord 2004, 80(2-3):173-179.

34. Patience DA, McGuire RJ, Scott Al, Freeman CP: The Edinburgh primary care depression study: personality disorder and outcome. Br J Psychiatry 1995, 167:324-330

35. Horwitz AV, Wakefield JC: The Loss of Sadness: How Psychiatry Transformed Normal Sorrow into Depressive Disorder. New York: Oxford University Press; 2007:305.

doi:10.1186/1751-0759-8-17

Cite this article as: Mercier et al.: Why do general practitioners prescribe antidepressants to their patients? A pilot study. BioPsychoSocial Medicine 2014 8:17.

\section{Submit your next manuscript to BioMed Central and take full advantage of:}

- Convenient online submission

- Thorough peer review

- No space constraints or color figure charges

- Immediate publication on acceptance

- Inclusion in PubMed, CAS, Scopus and Google Scholar

- Research which is freely available for redistribution

Submit your manuscript at www.biomedcentral.com/submit
C Biomed Central 